\title{
Experimental Investigation of Solar Greenhouse Drying of Hydroxide Sludge under Summer and Winter Climate
}

\author{
Fantasse Azeddine ${ }^{1 *}$, Lakhal EI Khadir ${ }^{1}$, Idlimam Ali ${ }^{2}$ \\ ${ }^{1}$ LMFE, Department of Physics, Cadi Ayyad University, Faculty of Sciences Semlalia, B.P. 2390, Marrakesh, Morocco \\ ${ }^{2}$ Team of Solar Energy and Medicinal Plants EESPAM, Teacher's Training College, PO Box 2400, \\ Cadi Ayyad University, Marrakesh, Morocco
}

Received: 11 March 2021

Accepted: 16 July 2021

\begin{abstract}
The valorization of the hydroxide sludge, from drinking water treatment plants and solar energy in Morocco, is the main aim of this contribution. In fact, the performance of open and closed solar greenhouse systems were analyzed by comparing with the external and internal meteorological conditions of this greenhouse. The hydroxide sludge from three different sites in the "Marrakech-Safi" region of Morocco was simultaneously dried inside the considered greenhouse. Moreover, the drying kinetic of the samples, during the drying process, was carried out. Based on the drying curves, it was found that the drying time depends on the temperature, higher temperature means shorter time and faster drying speed. In addition, it was revealed that the closed dryer, in the summer season, raises high temperatures and efficiency, and the drying time was reduced compared to the winter season. The moisture content at the end of the process was $71 \%$, the dryness of the sludge was increased from 14.7 to $80 \%$, the characteristic drying curves of the summer and winter periods were made. The cylindrical shape of the samples was constantly measured to follow the shrinkage as well as the geometric reduction of the product.
\end{abstract}

Keywords: drying, solar energy, hydroxide sludge, greenhouse, volume reduction

\section{Introduction}

During the process of drinking water production, coagulation and flocculation are usually the important steps in the clarification of water surface. The used coagulant and flocculant are often the aluminum sulfate and the polyelectrolyte. The reagents injected during treatment generate a large quantity of hydroxide sludge at the end of the cycle [1].

In general, the problem of treating sludge from drinking water plant is not considered in relation to the parameters related to water treatment [2]. Nevertheless, they are potential hazard to the environment. In fact, different technologies have been considered to treat and contribute to the recovery of this sludge, including landfilling, incineration or even agricultural spreading. The solar drying process of sludge waste in greenhouses

*e-mail: azeddinefantasse@gmail.com 
has been found as a sustainable development policy and it represents an important approach for their management [3]. By taking advantage mainly of solar energy to minimize the cost of the operation, solar drying in greenhouses has been used to reduce the mass and volume of such a product and thus limit the cost of storage, handling and transport. The high increase of sludge production makes the rational conception of greenhouse drying and the choice of treatment conditions essential for the development of optimal drying processes [4]. For example, Morocco's production of this waste is currently estimated at one million tons of liquid sludge per year and is expected to be increased for about $20 \%$ by 2030 [5]. Currently, the final destination of this sludge, in decreasing order of importance is:

- Agricultural spreading;

- Incineration;

- Landfilling.

With 3,000 hours of insolation per year and average irradiation of more than $5 \mathrm{kWh} / \mathrm{m}^{2}$, Morocco has considerable solar potential [5]. The greenhouse effect is based on the fact that the greenhouse walls and roof are made of specific materials with different properties in these two spectral ranges. These materials are transparent to solar radiation so they allow the sun's heat penetrates in the greenhouse but do not transmit infrared rays [6].

Sludge treatment is a combination of technically feasible, economically efficient and socially acceptable ways. It is probable, and even certain, that the current outlets will change in the years to come as a result of new regulatory requirements adopted primarily to regain confidence from the general public [7]. In this context, the upstream treatment of sludge, whose purpose is to condition the collected sludge in a form compatible with its intended use. Final destination, will also have to evolve [8]. Among the various advantages of the techniques of thermal drying in solar greenhouses are numerous, such as volume reduction, odour reduction, blocking of biological processes, etc. However, the high cost as well as the technological problems linked to the implementation of the processes or safety issues have been major obstacles to the development of this approach [9].

The general idea of drying is to provide energy to a solid-liquid mixture in order to extract the solvent that it contains. The thermal drying step of sludge after dewatering mechanics has various advantages both upstream of agricultural and industrial energetic recovery [10]. The target dryness depends on the application. When spreading, there is a tendency to push drying to completion, while partial drying is sometimes sought for incineration. The required input energy to dry the sludge can be transferred using modes of heat transfer: conduction, convection or radiation. A drying operation before spreading is required which allows in particular to meet the hygienization and stabilization requirements. These interests are as follows [11]:
- Reducing in volume and mass of sludge by the elimination of water.

- Decreasing the storage, transport and handling costs.

- Granulated sludge does not require any special maintenance during storage.

- Concentration of nutrients within the dry solid.

The drying of solar sludge uses this concept to speed up the process of water contained elimination in dewatered sludge. The heating of the sludge surface, due to solar and infrared radiation emitted by the transparent material of the greenhouse, increases the water vapour pressure at this surface and consequently promotes evaporation. A flow of fresh air admitted under the greenhouse allows the vapour to be evacuated of water from the drying system [12].

Nowadays, solar drying is convincing a large number of decision-makers due to its high performance, which is comparable to advanced thermal drying (final dryness between 60 and 90\%), and at a lower investment cost, but also because of the low operating costs that it generates [13]. Indeed, the installations are operating in fully automated mode (permanent monitoring are not required) which gives them great flexibility of use and operation by the operator. No handling in the greenhouse is necessary thanks to the sludge turnaround systems; the operations require only a few hours of workforce per week to transport and dispose of the sludge.

The heat transfers taking place during conventional solar drying are:

- Heating of the sludge by the solar flux transmitted through the greenhouse;

- Convective heat exchange between mud and air inside the greenhouse;

- Convective heat exchange between the greenhouse wall and the air inside it;

- Convective heat exchange between the greenhouse wall and the ambient air;

- Radiative exchange between the mud and the greenhouse wall;

- Radiative exchange between the greenhouse wall and the sky;

- Conductive exchange between the mud and the floor.

Mass transport is the transport of water vapour between the surface of the sludge and the air under the greenhouse. This transfer is assumed to be limited only by the evaporation of water vapour in the sludge surface without taking into account the influence of capillarity and diffusion inside the sludge on the steam transport [13].

In this context, thermal drying is considered as an intermediate stage in the sludge treatment operation before recovery of energy, material or storage. The advantages of drying in relation to the sludge issue as well as the technical and practical constraints linked to the expectations of the different participants in the sector will be presented in the next parts of this contribution [14]. 
The aim of this research paper is to study the solar drying process in greenhouses under experimental conditions, to understand the mechanisms and phenomena governing the behavior of the sludge during treatment as a function of the seasonal effect and the mode of energy input. Particular attention was paid to the kinetics and drying performance of sludge through a set of physical, microscopic and thermographic analysis methods.

\section{Materials and Methods}

\section{Interest of the Process}

Solar drying is an important process for the management of drinking water sludge as it can reduce the mass and volume of this waste and consequently the cost of storage, handling and transport. This is mainly due to the benefit of free solar energy. In addition, it has a significant impact on the reduction of pathogens [15]. Table 1 shows the solar drying performance in terms of final dryness compared to different current sludge dewatering approaches.

\section{Description of CNEREE Greenhouse}

The concept of the current solar sludge drying processes is based on the use of greenhouse effect to heat both the indoor air and the sludge in order to increase drying speed. The thermal flux, transmitted by convection and radiation, heats the sludge and allows the evaporation of the water which they contain. A typical schematization of a greenhouse is illustrated in Fig. 1.

The present experimental study was conducted on a pilot sludge dryer located at the CNEREE laboratory, in Marrakech city which the climate is arid with temperate winters. The temperature typically ranges from 7 to $42^{\circ} \mathrm{C}$ and is rarely below $5^{\circ} \mathrm{C}$ or above $45^{\circ} \mathrm{C}$. The sludge undergoes mechanical dewatering in a centrifuge before arriving in the greenhouse, which gives it a dryness of

Table 1. Final envisaged dryness for each type of treatment.

\begin{tabular}{|c|c|}
\hline Main process & Expected dryness \\
\hline $\begin{array}{c}\text { Centrifuge with chemical } \\
\text { conditioning }\end{array}$ & Approximately $20 \%$ \\
\hline Filter press & $\begin{array}{c}25-28 \% \text { for packaging } \\
\text { with synthetic polymers } \\
30-35 \% \text { for limed sludge }\end{array}$ \\
\hline $\begin{array}{c}\text { Drying beds planted with reeds } \\
\text { (natural drying) }\end{array}$ & $\begin{array}{c}15-25 \% \text { depending on } \\
\text { meteorological conditions } \\
\text { and operational practices }\end{array}$ \\
\hline Solar drying & $\begin{array}{c}\text { Flexible }(60-90 \%) \\
\text { Normally } 70-75 \%\end{array}$ \\
\hline Thermal dryer & $60-92 \%$ \\
\hline
\end{tabular}

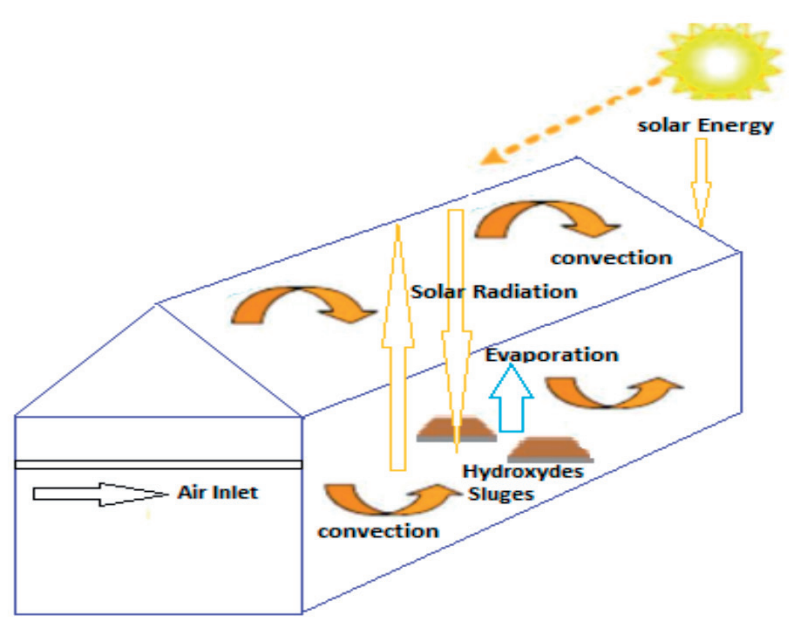

Fig. 1. Energy flow in an even-span style greenhouse.

about $18 \%$ at the beginning of the drying cycle. The used greenhouse is a tunnel one with even-span style, with a width of $60 \mathrm{~cm}$ and a length of $160 \mathrm{~cm}$. the dryer is constructed with galvanized steel covered with transparent polycarbonate plates, resistant to hail, wind and snow. The height of the roof is $80 \mathrm{~cm}$ with a $30 \mathrm{~cm}$ high chimney with two sides in the form of a window in order to allow natural convection. The floor is a layer of cement $(10 \mathrm{~cm})$ covered with black plastic. For each experiment, the quantity dried can be estimated at $15 \mathrm{~kg} / \mathrm{m}^{2}$. An illustration of the used greenhouse is shown in Fig. 2.

To obtain an optimal greenhouse effect, the used materials, to build the dryer, must transmit sufficient
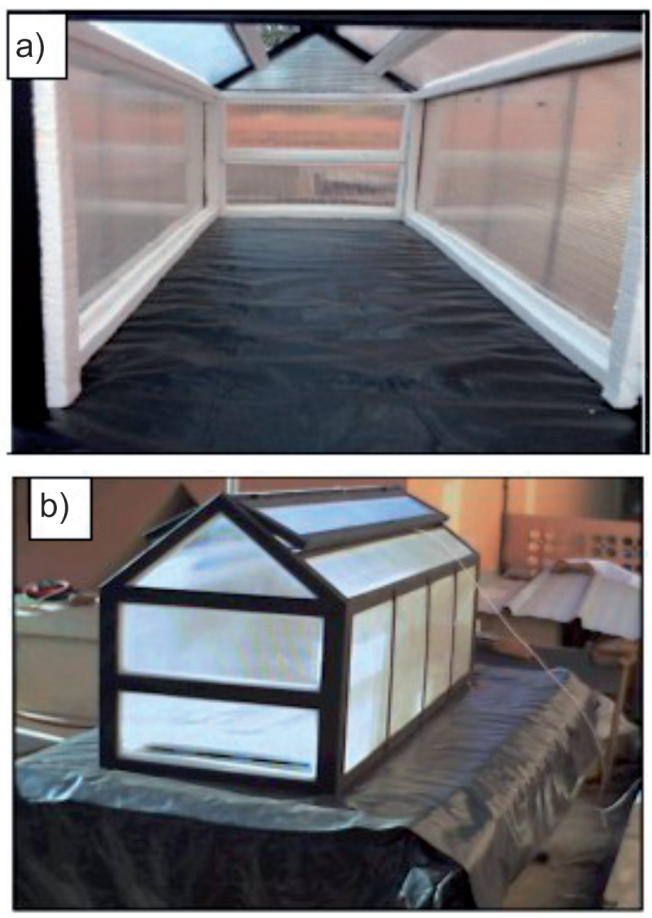

Fig. 2. Indoor a) and outdoor b) views of the used greenhouse. 
Table 2. Physical and chemical proprieties of hydroxide sludge samples.

\begin{tabular}{|c|c|}
\hline Propriety & Value \\
\hline Moisture content (\%) & $75 \pm 5$ \\
\hline Volatile solids (\% DS) & $21 \pm 2$ \\
\hline $\mathrm{pH}(-)$ & $6.85 \pm 2$ \\
\hline Suspended material's (m/l) & $19.6 \pm 1$ \\
\hline Silica (mg/g) & $47.8 \pm 3$ \\
\hline Alumina (mg/g) & $28 \pm 3$ \\
\hline Iron $(\mathrm{mg} / \mathrm{g})$ & $10.3 \pm 2$ \\
\hline Calcium $(\mathrm{mg} / \mathrm{g})$ & $4.4 \pm 1$ \\
\hline Magnesium $(\mathrm{mg} / \mathrm{g})$ & $3.9 \pm 1$ \\
\hline
\end{tabular}

sunlight into the greenhouse and minimize the heat lost. Also, the cost of these materials should be reasonable. A compromise between the different properties leads to the most efficient choice of polycarbonate for solar drying. The main part of the drying pilot was made of galvanized steel covered with a $1 \mathrm{~cm}$ thick transparent polycarbonate sheet. This material allows both sufficient light transmission and heat conservation inside the greenhouse.

\section{Collection of Sludge Samples}

Fresh sludge samples were collected from the waste sludge containers of the DWTP in Safi, Marrakech and El kelaa des Sraghna cities. The physical and chemical characteristics of the samples are presented in Table 2. All samples were taken from the accumulated residues during the primary and secondary treatment of the three stations (see Fig. 3). The samples were made up of 40 cylindrical cakes divided into two parts, 20 samples were studied during the winter season and the others during in the summer season. The samples were divided into three volumes ranging from large to small respectively, in order to compare the drying performance between them. The first volume $\mathrm{V}_{1}$ was $56 \mathrm{~cm}^{3}$, the second volume $\mathrm{V}_{2}$ was $20 \mathrm{~cm}^{3}$ and the third volume $\mathrm{V}_{3} 6 \mathrm{~cm}^{3}$. The average sample weight for the three volumes was 40,30 and $20 \mathrm{~g}$, respectively.

\section{Drying Conditions}

The experimental drying process was programmed for summer and winter. the experiments started in the hot season on July 18, 2019 at 08:00 a.m and in the cold season on January 16, 2020 at 08:00 a.m. The two experiments ended when the samples reached a moisture content corresponding to a dryness of $80 \%$. Changes in temperature, relative humidity and air velocity were recorded inside and outside the drying pilot and continuously recorded with a multifunctional precision measuring instrument (Testo 400), the recording interval being scheduled for 5 minutes. Masstaking of the samples was captured every hour. The dry matter (DM) content of the sludge was determined by measuring the dry weight using a drying oven at $105^{\circ} \mathrm{C}$ until a constant mass is recorded. In addition, the volume of the sample was measured during all the drying tests by assessing the diameter and height of the cylindrical mud cakes.

\section{Results and Discussion}

\section{Climate Conditions}

The meteorological parameters (temperature and humidity) were recorded during hot and cold periods. The experimental data are shown in Fig. 4 and Fig. 5. Fig. 4a) illustrates the variation of temperature and humidity, inside the greenhouse during winter season, over time. Fig. $4 b$ ) presents this variation in the outside of the greenhouse. It can be seen that the inside temperatures were always higher than the outdoor ones. They varied from 25 to $45^{\circ} \mathrm{C}$ during the day in winter. These results are confirmed by several previous studies [16]. However, there were no significant differences in

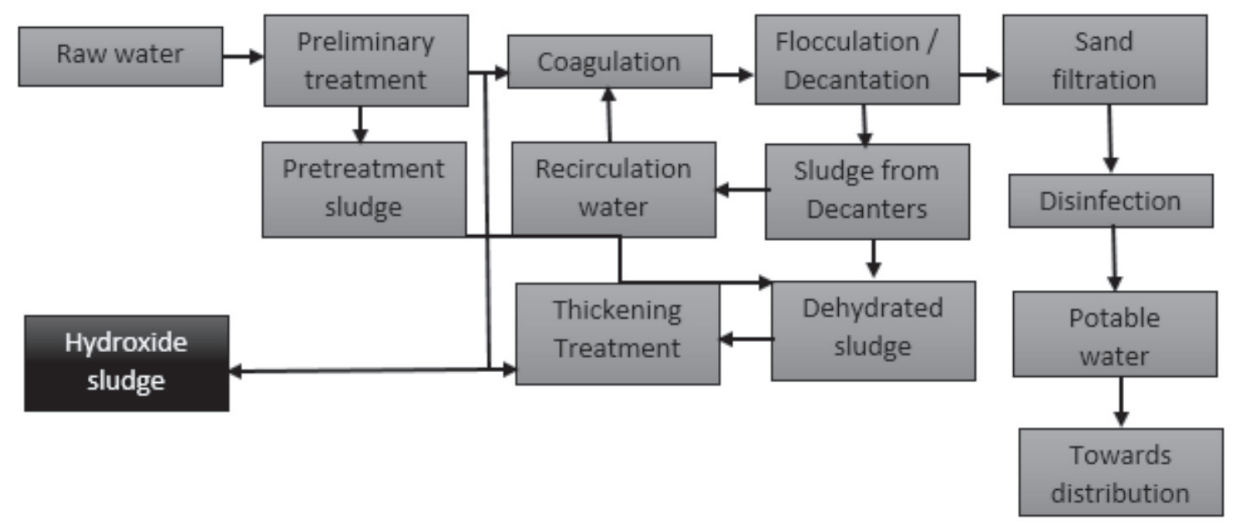

Fig. 3. Process diagram of DWTS. 

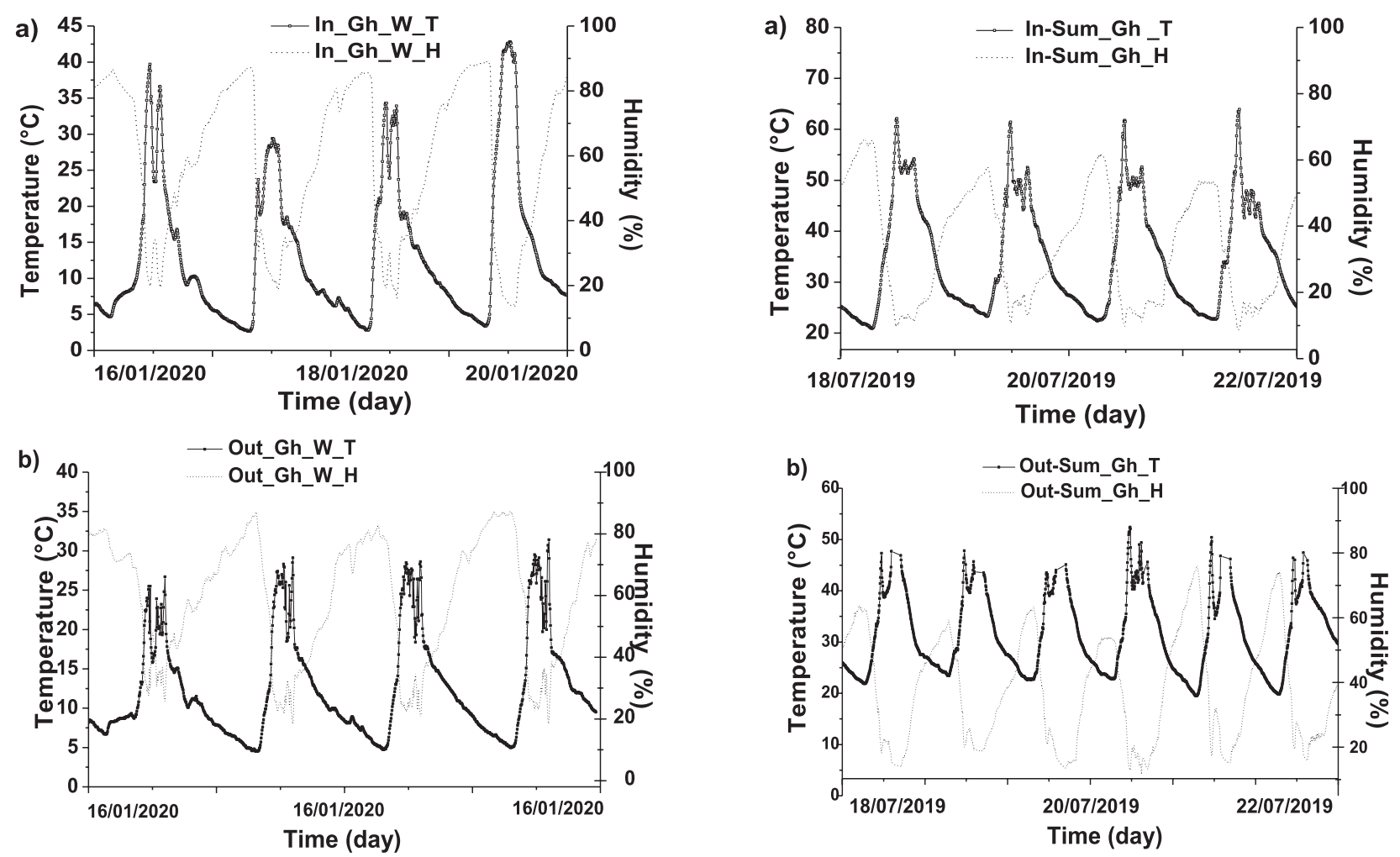

Fig. 4. Temperature and humidity at the entrance a) and exit b) of the greenhouse in the winter season.

the temperature and humidity values inside and outside the greenhouse in the case of open and closed types in the winter season. The fluctuation in temperature and relative humidity inside the greenhouse was similar to that of outdoor ambient conditions due to the chosen type of greenhouse.

In general, the open greenhouse is very dependent on weather conditions [16], [17], and this represents the main drawback of this type of greenhouse. On the other hand, the open greenhouse is the simplest, the most ecological and the least expensive solution compared to the closed greenhouse since it requires less equipment [17].

Fig. 5 shows the variations in temperature and relative humidity inside (Fig. 5a) and outside (Fig. 5b) the drying pilot in summer. The highest temperatures were recorded during the daily period from 11:00 to $15: 00$ which are varied from 50 to $65^{\circ} \mathrm{C}$. These temperatures followed the rise in ambient temperatures, which actually did not exceed 40 to $48^{\circ} \mathrm{C}$ during the day.

The pilot's artificial greenhouse effect was easily noted due to the significant difference in temperature between the inside and outside of the greenhouse, which could sometimes reach $25^{\circ} \mathrm{C}$ in the case of the closed greenhouse. In comparison with the results obtained from the experiment of drying in the open greenhouse, this difference hardly exceeded $10^{\circ} \mathrm{C}$. During the night, the average temperatures inside the greenhouse were slightly lower than the ambient ones with an average
Fig. 5. Temperature and humidity at the entrance a) and exit b) of the greenhouse in the summer season.

difference of $4^{\circ} \mathrm{C}$. Fig. 4 and Fig. 5 showed that this did not really have a direct effect on the temperature of the sludge inside the greenhouse, which always maintains a warm internal temperature compared to the model sludge at night. Similar to the results obtained in the previous experiments, the relative humidity values measured inside the pilot at night exceeded those during the day.

Fig. 6 presents wind speed measurements, it showed that the values in the open greenhouse were significantly higher than those recorded inside the closed greenhouse in the experiments performed. This is beneficial as sludge drying was able to achieve significant DM levels in summer and winter. This can be explained by the strong influence of the wind on the drying speed. In return, the sludge treated by the open drying greenhouses was almost exposed to all weather conditions outside. No rain was observed during the experiments. However, this could directly affect the performance of this process and decrease the DM content of the sludge at any time. This is explained in the present experiments by the fall in wind speeds at night (Fig. 6). This fluctuation in relative humidity inside and outside the greenhouse was similar to the results obtained by [18].

\section{Geometric Parameters Monitoring}

During drying, the geometric dimensions of the samples were measured constantly in hot and cold 


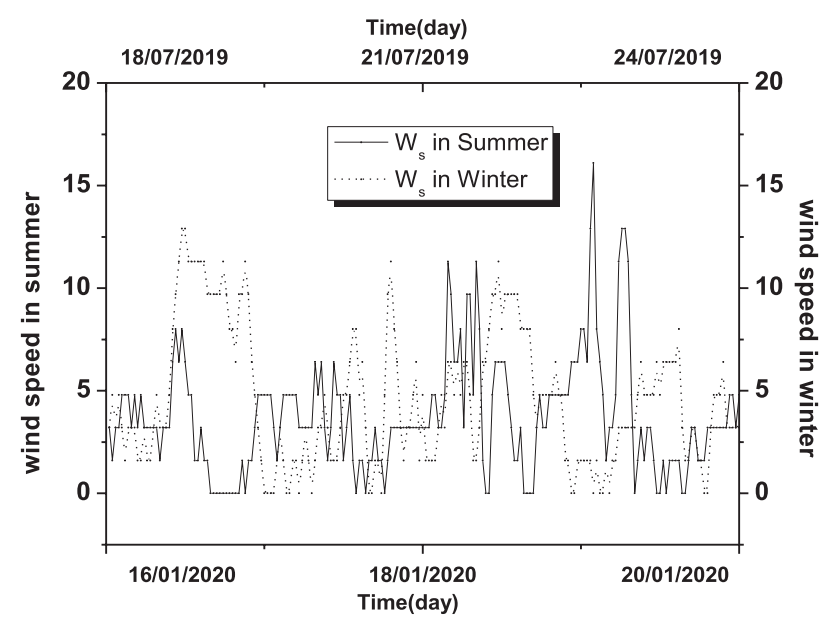

Fig. 6. Wind speed during both summer and winter periods.

periods in the arid climate of the city of Marrakech. The volumes of sample were calculated based on the diameter and height measurements. The results showed in Table 3 a significant volume reduction due to the loss of water during drying. In fact, after only 6 hours in summer and 10 hours in winter of drying, the sample volumes were reduced for about $70 \%$. No significant difference in reduction of the volumes of $\mathrm{S}_{\mathrm{m}}, \mathrm{S}_{\mathrm{k}}$ or $\mathrm{S}_{\mathrm{s}}$ sludge was observed between the two campaigns, despite the high temperatures measured inside the greenhouse during the hot season. This can be explained by the high air speed measured in the cold season campaign, which significantly participates in the evacuation of the saturated air accumulated in the drying pilot.

The occurrence of shrinkage and cracking took place on $\mathrm{S}_{\mathrm{m}}, \mathrm{S}_{\mathrm{k}}$ or $\mathrm{S}_{\mathrm{s}}$ sludges during the 2 drying campaigns. Following the changes in the shape of the samples shown in Table 3, it was shown that the shrinkage began to appear after only 4 hours of drying in the hot season and after 8 hours in the cold season campaigns. The shrinkage is a result of the reduction in product size caused by water loss from the sludge during drying. The first signs of cracking also appeared as a result of moisture evaporation. Likewise, shrinkage and cracking have been observed during the sludge drying process by [19]. The 2D cross-sectional images of the sludge samples (Table 3) showed a considerable reduction in product volume. These images processed by the Image $\mathrm{J}$ software confirmed the significant reduction in the diameter of the sludge during the first 6 hours of drying in the hot period and the first 10 hours in the cold period for the $\mathrm{S}_{\mathrm{m}}, \mathrm{S}_{\mathrm{k}}$ or $\mathrm{S}_{\mathrm{s}}$ samples. Beyond these periods of time, only the reduction in the height of the samples can be considered as significant.

Interpretations of these two slowdowns differ somewhat depending on the model mentioned. Two models are commonly cited: the 'receding front model' and the 'wetted-surface model' [19]. The first model assumes that the first period of slowdown begins when the surface of the material in contact with hot air reaches the hygroscopic threshold. The drying front

Table 3. Drying of the three samples of hydroxide sludge Sk, Ss and Sm during the optimal summer period in a closed greenhouse.

\begin{tabular}{|c|c|c|c|c|c|c|}
\hline \multirow{2}{*}{ Samples } & \multicolumn{2}{|c|}{ Volume 1} & \multicolumn{2}{|c|}{ Volume 2} & \multicolumn{2}{|c|}{ Volume 3} \\
\hline & Initial & Final & Initial & Final & Initial & Final \\
\hline $\mathrm{S}_{\mathrm{k}}$ & & & & & & \\
\hline Weights & $40.32 \mathrm{~g} / \mathrm{g}$ & $1.08 \mathrm{~g} / \mathrm{g}$ & $30.12 \mathrm{~g} / \mathrm{g}$ & $0.95 \mathrm{~g} / \mathrm{g}$ & $20.54 \mathrm{~g} / \mathrm{g}$ & $0.86 \mathrm{~g} / \mathrm{g}$ \\
\hline $\mathrm{S}_{\mathrm{s}}$ & & & & & & \\
\hline Weights & $41.26 \mathrm{~g} / \mathrm{g}$ & $1.06 \mathrm{~g} / \mathrm{g}$ & $30.45 \mathrm{~g} / \mathrm{g}$ & $0.9 \mathrm{~g} / \mathrm{g}$ & $20.89 \mathrm{~g} / \mathrm{g}$ & $0.90 \mathrm{~g} / \mathrm{g}$ \\
\hline $\mathrm{S}_{\mathrm{m}}$ & & & & & & \\
\hline Weights & $40.5 \mathrm{~g} / \mathrm{g}$ & $0.97 \mathrm{~g} / \mathrm{g}$ & $30.33 \mathrm{~g} / \mathrm{g}$ & $0.92 \mathrm{~g} / \mathrm{g}$ & $20.12 \mathrm{~g} / \mathrm{g}$ & $0.83 \mathrm{~g} / \mathrm{g}$ \\
\hline
\end{tabular}


which is on the surface migrates towards the interior of the material. In this phase, it is the different internal resistances of the material that control the drying speed. These resistances will be even greater than the drying front and are located far from the external surface of the material [20].

Once all of the material is in the hygroscopic range (all that remains is bound water) the second slowing down phase begins. Drying is finished when the solid has reached its equilibrium water content $\left(\mathrm{X}_{\mathrm{eq}}\right)$. The second 'wetted-surface model' admits that the drop in drying speed is related to the appearance of dry areas on the surface of the material, corresponding to an overall water content. However, if the speed is related to the wetted surface fraction, the latter is constant. This period continues until complete drying of the outer surface. The second slowdown zone is a reflection of a speed control by the diffusion of water inside the material. Drying ends at maximum dryness or at $X_{\mathrm{eq}}$ for hygroscopic materials. The drying front can also withdraw into the material and then the first model can be found. Usually the dried product goes through several phases and the number of these phases varies from one product to the other and depends on the drying method used and the operating conditions [21].
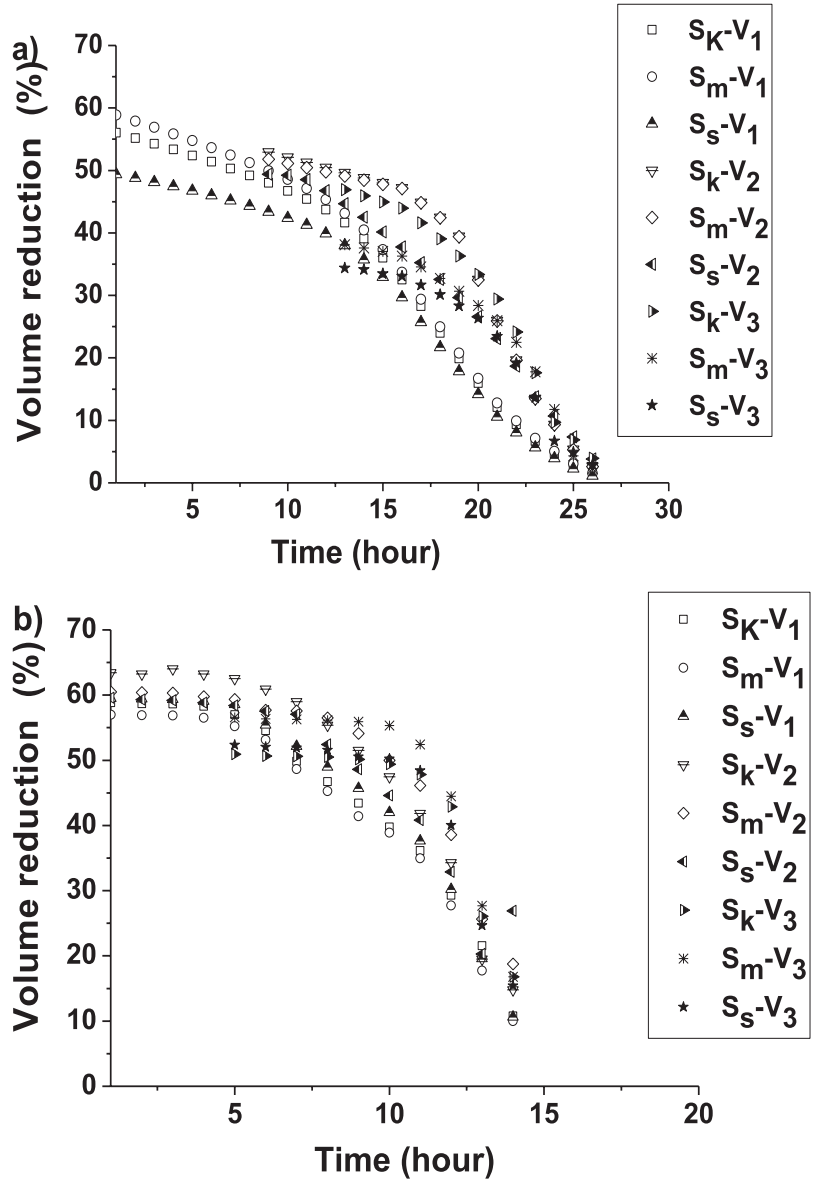

Fig. 7. Reduced volume of samples in winter a) and summer b).
The end of these experimental campaigns is characterized by a significant reduction in the volume of dried products, which represents at least $70 \%$ of the initial volume of sludge during the two seasons. In our case, no energy consumption was required in addition to solar energy to reduce the volume of sludge. Thus, this process allows a significant energy saving given that the specific energy consumption of conventional convective dryers varies from $700 \mathrm{kWh} / \mathrm{t}$ to $1400 \mathrm{kWh} / \mathrm{t}$ of evaporated water from $800 \mathrm{kWh} / \mathrm{t}$. $\mathrm{t}$ at $955 \mathrm{kWh} / \mathrm{t}$ of evaporated water for conventional conductive dryers [22].

Fig. 7 shows the volume reduction curve of the samples dried by the optimized solar pilot, compared to that of the control samples. The results obtained showed a significant reduction in the volume of these samples due to the loss of water during drying. In fact, the sample volumes were reduced by half after 10 hours of drying in a greenhouse in winter for the smallest volumes $\mathrm{V}_{3}$ and 20 hours for the largest volumes $\mathrm{V}_{1}$, for drying in a greenhouse in summer. The volumes of the samples were reduced to half after 8 hours for the smallest volumes $\mathrm{V}_{1}$ and 12 hours for the large volumes $\mathrm{V}_{1}$. The final reduction in volume obtained after 30 hours of pilot drying was $61 \%$ in the case of the cold campaign, while the reduction in the model sludge was $70 \%$ in the hot period. The latter was recorded at 20 hours of drying.

\section{Kinetics of Hydroxide Sludge Drying}

\section{Case of the Winter Season}

\section{Open Greenhouse}

An open greenhouse relies more on the natural circulation of air; therefore, it is equipped, at a minimum, with openings located at the bottom and top of it. It has no door. This concept is based on natural convection where hot air rises due to its lower density compared to cold air [23]. The path of the air can be explained as follows: cold air enters through the openings located at the bottom of the greenhouse, mixes with the ambient air located inside so its temperature increases, which causes a transfer of heat and mass with the sludge bed and then leaves the greenhouse through the openings located at the top. The reality is much more complex and the air that enters the greenhouse can stay there for a very long time by making several exchange loops with the mud and the ambient air.

As shown in Fig. 8a), the water content of the samples decreased from about 1 to $0.002 \mathrm{~kg}$ water $/ \mathrm{kg}$ DM in cold period in 25 hours. In addition, these results show that after 5 hours of drying in a greenhouse, the dryness of the sludge exceeded $50 \%$ for small volumes $\mathrm{V}_{3}$ and $30 \%$ for large volumes $\mathrm{V}_{1}$ in the cold season. This greenhouse solar drying time was 
significantly lower compared to 64-83 days in Northern Europe [24] and 7-12 days in Southern Europe [25]. The drying behavior of sewage sludge during solar drying depends on the origin of the sludge.

In the case of Fig. 8b) and Fig. 8c), which deal respectively with the drying speed in terms of time and water content, the drying speed recorded during the cold season was affected by the weather conditions. The samples showed an absence of a constant speed drying period and the presence of a drying speed slowing period from the start of the application of the drying process. It was observed that the highest value of the drying rate obtained in winter was $0.140 \mathrm{~kg}$ of water $/ \mathrm{kg}$ MS.h. The maximum values noted for each volume were $0.06 \mathrm{~kg}$ of water $/ \mathrm{kg}$ MS.h for small volumes $\mathrm{V}_{3}$, $0.1 \mathrm{~kg}$ of water $/ \mathrm{kg}$ MS.h for medium volumes $\mathrm{V}_{2}$ and $0.14 \mathrm{~kg}$ of water $/ \mathrm{kg}$ MS.h for large volumes $\mathrm{V}_{1}$. In view of the above, it can be deduced that the drying speed increases during high radiation, high temperatures and high wind speeds. In general, the drying rates obtained in this comparative study are considered to be similar to those recorded in the drying trials [26].

\section{Closed Greenhouse}

A closed greenhouse uses calculated and optimized air flow using a control unit that measures weather conditions (temperature, humidity, solar radiation, wind speed). Thus, a well-controlled amount of air enters the greenhouse and allows the sludge to be dried effectively without reducing the interior temperature too much, then it comes out once it is too humid. The closed greenhouse therefore makes it possible to control the rate of air renewal, which results in dried sludge of better quality. The end product is then much less dependent on weather conditions.

In the case of the closed greenhouse, the sludge $S_{\mathrm{s}}$, $\mathrm{S}_{\mathrm{m}}$ and $\mathrm{S}_{\mathrm{k}}$ had different behaviors. As shown in Fig. 9a), it is evident that the sludge drying rate during the winter season in the case of the closed greenhouse was affected by the change in weather conditions. The samples showed an absence of the period of the constant rate drying and the presence of a period of slowing drying rate since the start of the application of the drying process Fig. 9b). This result shows that our mechanically dehydrated DWTS samples no longer contained free water, and that solar drying treatment in the greenhouse affected only their fraction of bound water.

This is confirmed by the work of [27], which qualify free water as that which could be eliminated by mechanical dehydration. Nevertheless, it was observed that the highest values of water content were obtained with a maximum value of $1.2 \mathrm{~kg}$ of water $/ \mathrm{kg}$ DM and a minimum value of $0.0019 \mathrm{~kg}$ of water $/ \mathrm{kg} \mathrm{DM}$ for the largest volume $\mathrm{V}_{1}$, for the three samples $\mathrm{S}_{\mathrm{k}}, \mathrm{S}_{\mathrm{s}}$ and $\mathrm{S}_{\mathrm{m}}$; a maximum value of $1.015 \mathrm{~kg}$ of water $/ \mathrm{kg} \mathrm{DM}$ and a minimum of $0.0016 \mathrm{~kg}$ of water $/ \mathrm{kg} \mathrm{DM}$ for $\mathrm{V}_{2}$ and a maximum value of $0.85 \mathrm{~kg}$ of water $/ \mathrm{kg} \mathrm{DM}$ and a minimum of $0.00991 \mathrm{~kg}$ of water $/ \mathrm{kg} \mathrm{DM}$ for the volume $\mathrm{V}_{3}$. The drying time in the cold period in the case of the closed greenhouse was 25 hours for large volumes $\mathrm{V}_{1}$. Hence, it decreases by decreasing the volume. In addition, our results showed that after 5 hours of drying in the greenhouse, the dryness of the sludge exceeded $50 \%$ for small volumes $\mathrm{V}_{3}$ and $30 \%$ for large volumes $\mathrm{V}_{1}$ in the cold season.
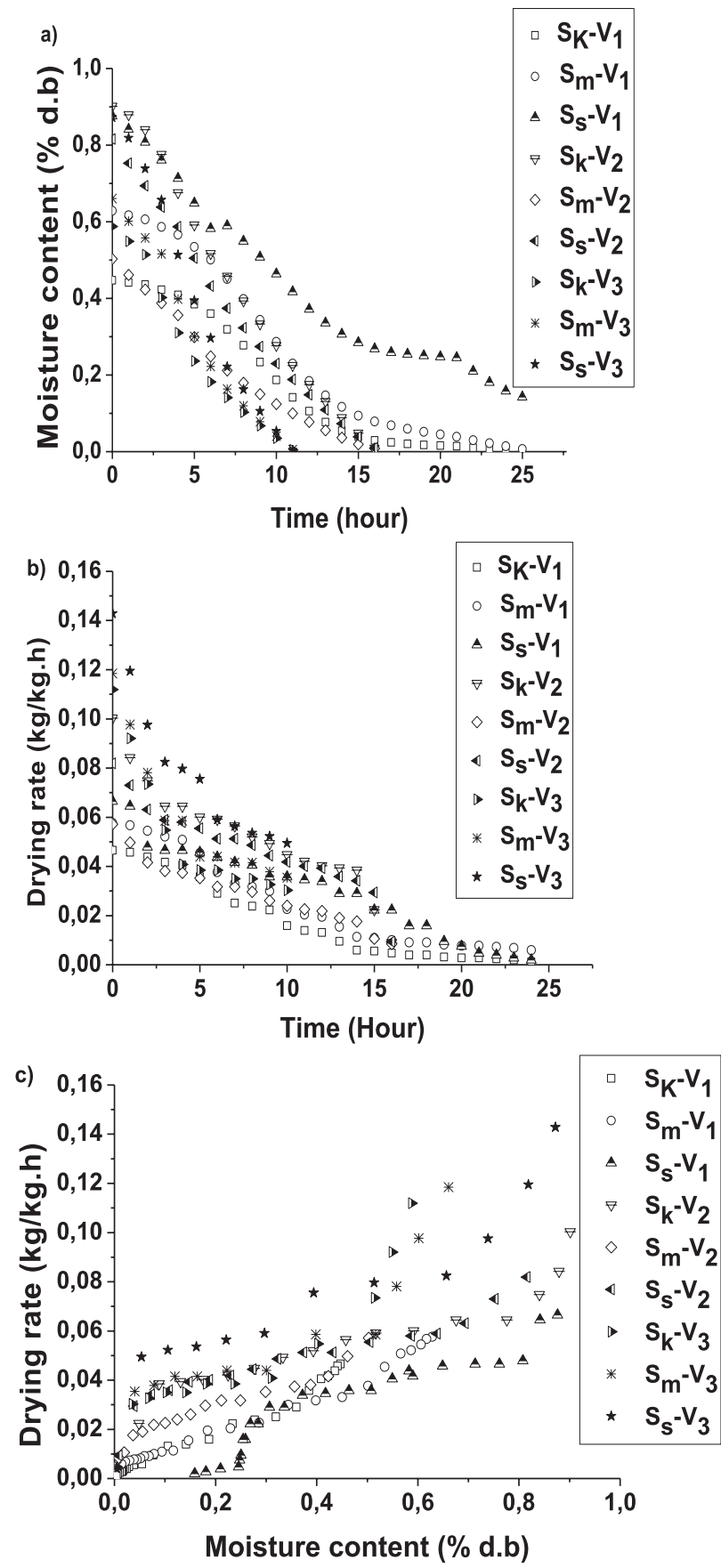

Fig. 8. Drying kinetics of the three samples under open greenhouse in cold season; a) moisture content as a function as time, b) drying rate as a function as time and c) moisture content as a function as drying rate. 


\section{Case of the Summer Season}

\section{Open Greenhouse}

The temperature inside the drying pilot during the summer period was between 50 and $65^{\circ} \mathrm{C}$. It was always higher than the outside temperature values, which varied from 40 to $48^{\circ} \mathrm{C}$. These results were found by several previous studies [28]. In fact, the greenhouses indoor temperatures were higher in hot weather than the ambient outdoor temperatures. As can be seen in Fig. 10 the water content of the samples decreased from about $1.84 \mathrm{~kg}$ of water $/ \mathrm{kg} \mathrm{DM}$ to $0.008 \mathrm{~kg}$ of
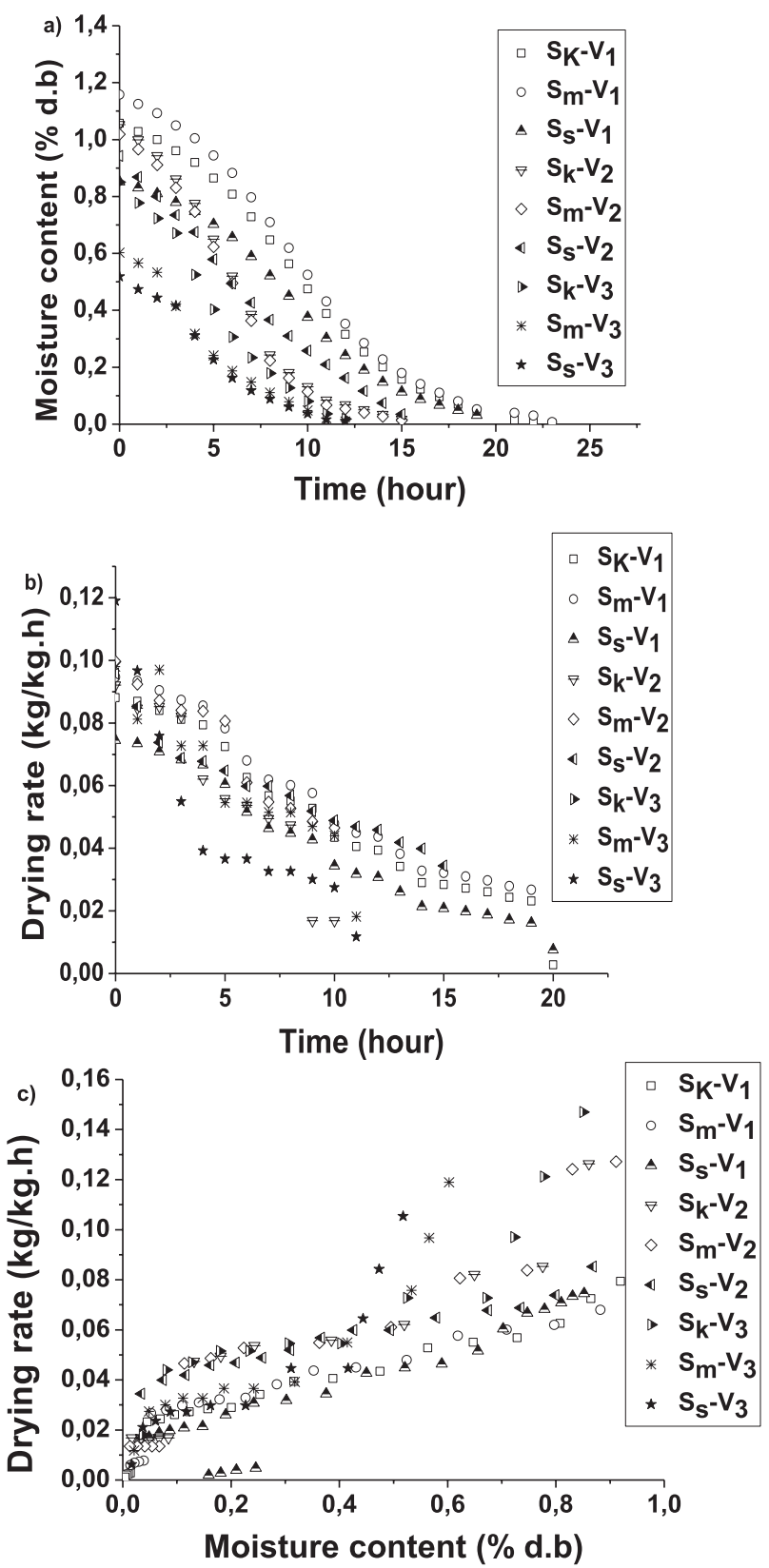

Fig. 9. Drying kinetics of the three samples under closed greenhouse in cold season; a) moisture content as a function as time, b) drying rate as a function as time and c) moisture content as a function as drying rate. water $/ \mathrm{kg} \mathrm{DM}$ for $\mathrm{V}_{1}$. For $\mathrm{V}_{2}$ the water content of the samples decreased from about $1.31 \mathrm{~kg}$ of water $/ \mathrm{kg} \mathrm{DM}$ to $0.003 \mathrm{~kg}$ of water $/ \mathrm{kg} \mathrm{DM}$, while for $\mathrm{V}_{3}$ it decreased from about $1.06 \mathrm{~kg}$ of water $/ \mathrm{kg} \mathrm{DM}$ to $0.002 \mathrm{~kg}$ of water $/ \mathrm{kg}$ of DM. Furthermore, the present results show that after 5 hours of drying in a closed greenhouse, we exceeded $70 \%$ for small, medium and large volumes; the dryness of the three hydroxide sludge samples exceeded $80 \%$ in the hot season.

a)
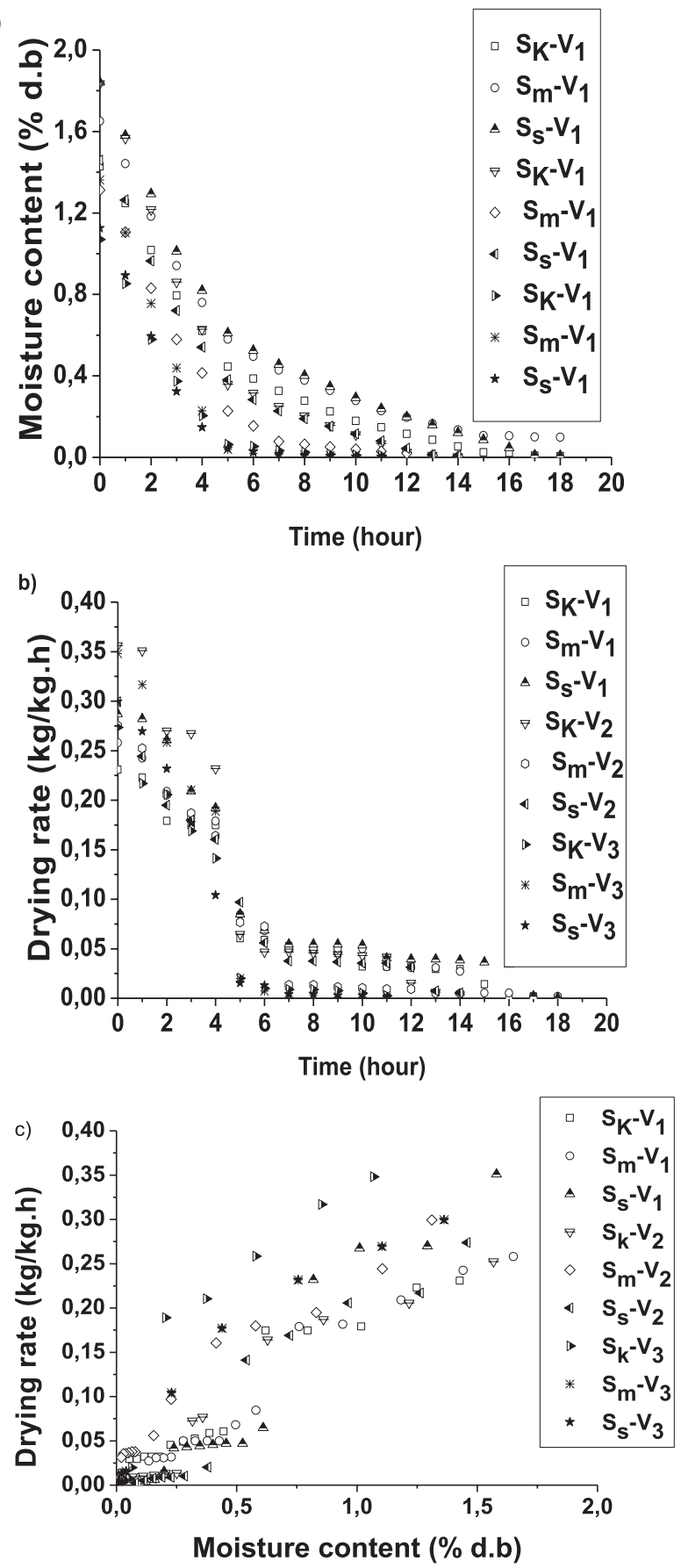

Fig. 10. Drying kinetics of the three samples under open greenhouse in the summer season; a) moisture content as a function as time, b) drying rate as a function as time and c) moisture content as a function as drying rate. 


\section{Closed Greenhouse}

The drying behavior of sludge during solar drying depends on the origin of the sludge [28]. In the present study, it should be mentioned that the $\mathrm{S}_{\mathrm{k}}, \mathrm{S}_{\mathrm{s}}$ and $\mathrm{S}_{\mathrm{m}}$ sludge samples were collected from different plants. As shown in Fig. 11, it is evident that the rate of sludge drying during the summer season is affected by changing in weather conditions Fig 11a). The results presented in Fig. 11b) and Fig. 11c) show the influence
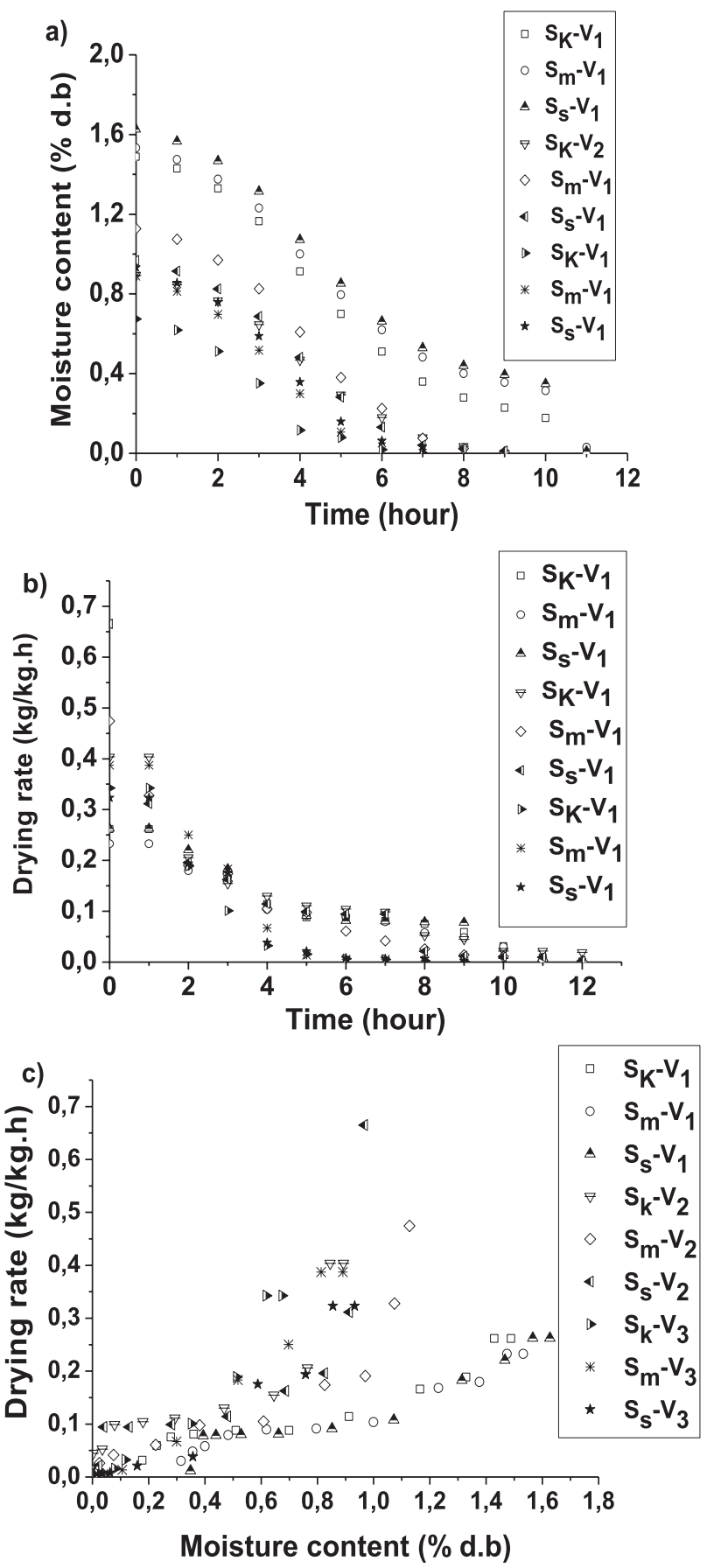

Fig. 11. Drying kinetics of the three samples under close greenhouse in the summer season; a) moisture content as a function as time, b) drying rate as a function as time and c) moisture content as a function as drying rate. of the high temperature inside the greenhouse and the high temperature outside. The water content of the samples decreased from approximately 1.65 to $0.011 \mathrm{~kg}$ of water $/ \mathrm{kg} \mathrm{DM}$ for $\mathrm{V}_{1}$, for $\mathrm{V}_{2}$ the water content of the samples decreased from approximately 1.12 to $0.002 \mathrm{~kg}$ water/kg DM, while for $\mathrm{V}_{3}$ the water content of the samples decreased from approximately 0.932 to 0.0014 $\mathrm{kg}$ water $/ \mathrm{kg}$ of DM in hot periods in just 12 hours.

It should be noted that after only 6 hours of drying, the small volumes were dried. As for the large volumes, they exceeded $50 \%$. This drying time was significantly shorter compared to the periods recorded in several studies [29]. The analysis of the drying kinetics in Fig. 11c) which presents the evolution of the drying speeds of the dried sludge in a closed greenhouse, shows the non-existence of a clear pre-heating period and the period at constant speed. It was observed that the highest values of the drying rates which were obtained in summer had a maximum of $0.7 \mathrm{~kg}$ of water $/ \mathrm{kg}$ MS.h for the closed process. The drying speed, therefore, depends mainly on external conditions, including air speed, humidity and temperature of the drying agent
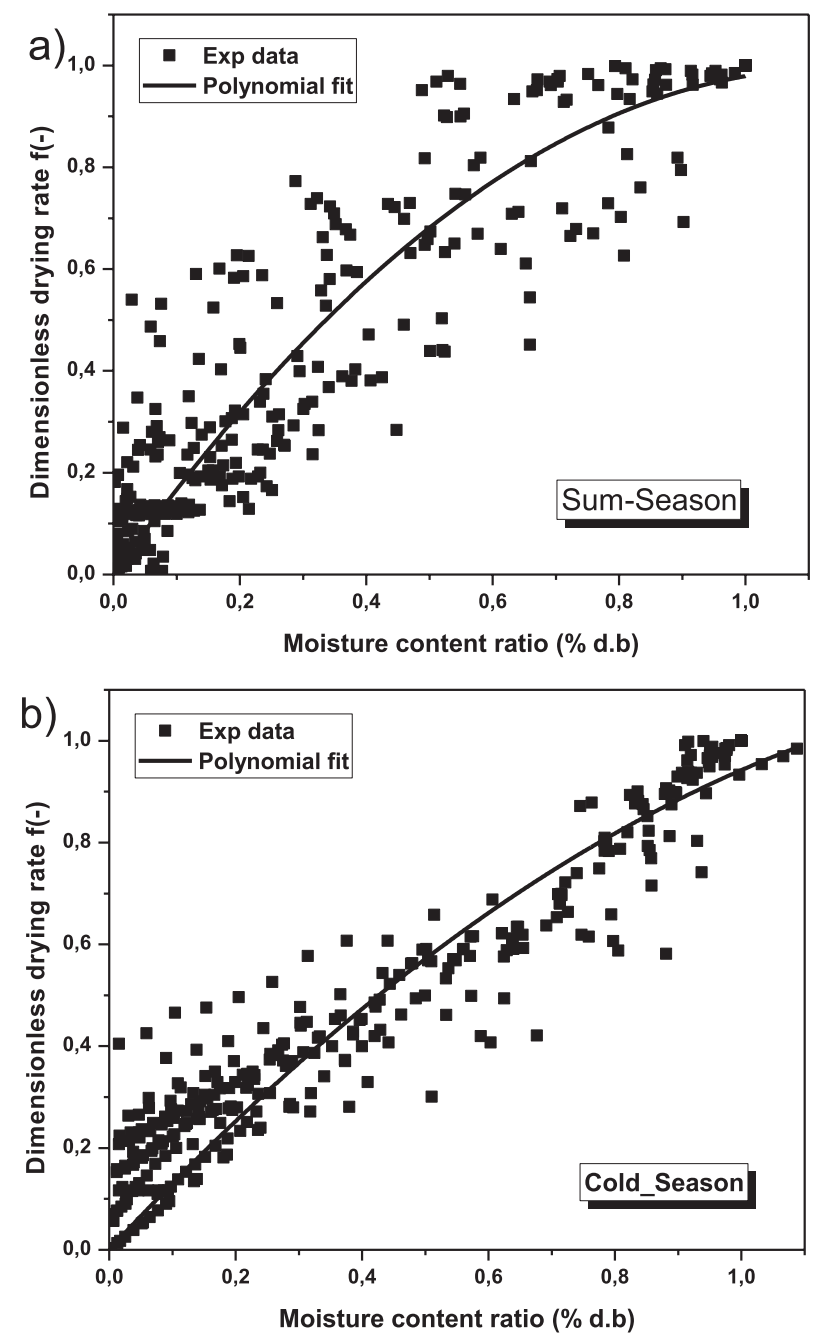

Fig. 12. Characteristic drying curve of the three sludge into summer a) and cold b) season. 
and the surface exposed to drying [30]. In other words, the initial dryness of the samples increased from 14.7 to $80 \%$ after applying this treatment. In fact, the DM rate of $50 \%$ was obtained only in 6 hours. In addition, drying in the closed greenhouse is faster than that in an open greenhouse.

\section{Characteristic Drying Curve (CDC)}

Characteristic drying curve is a useful tool that allows to establish an empirical law of greenhouse drying, taking into consideration the experimental results. This approach leads to a total understanding of the drying process under various aero-thermal conditions. Fig. 12 presents the CDC of DWTS in the different meteorological conditions, summer Fig. 12a) and cold Fig. 12b). From the graph, there is a high concentration of the points in the interval $0-0.6 \%$ for the summer season and an interval $0-0.7 \%$ for the cold season, which indicates the possibility of the product's storage for extended periods.

Using computer software "Origin 8", a non-linear optimization method of the drying experimental results leads to identify the characteristic drying curve in the form of a polynomial equation of second degree.

$$
\begin{aligned}
& \mathrm{f}_{\mathrm{s}}=1.74578 \mathrm{X}-0.76673 \mathrm{X}^{2} \\
& \mathrm{f}_{w}=1.34366 \mathrm{X}-0.40135 \mathrm{X}^{2}
\end{aligned}
$$

The polynomial model adjusts the characteristic drying curve with a standard error of 0.063 and 0.047 , a correlation coefficient of 0.9987 and 0.9897 respectively for the summer and the winter, which confirms the efficiency of the adjustment.

\section{Conclusions}

The objective of this paper is to contribute to the valorization of sludge from drinking water treatment plants in Morocco, using solar energy. This study revealed the effective treatment of hydroxide sludge by solar drying in an open and closed greenhouse in hot and cold periods in the city of Marrakech in particular, and in areas with an arid climate in general. The comparison between three samples from three drinking water treatment plants $\mathrm{S}_{\mathrm{k}}, \mathrm{S}_{\mathrm{s}}$ and $\mathrm{S}_{\mathrm{m}}$ was performed. These samples had three different volumes in order to assess the effect of volume on greenhouse drying. The effect of volume was significant. In fact, when the considered volume is low, the drying time decreases and the drying effect increases. The maximum water content of the samples decreased from approximately 1 to $0.002 \mathrm{~kg}$ of water $/ \mathrm{kg} \mathrm{DM}$ and from 1.2 to $0.006 \mathrm{~kg}$ of water $/ \mathrm{kg}$ DM for both types of greenhouse, open and closed, in cold periods, in only 30 hours and 25 hours, respectively. For the hot period, the maximum water content of the samples decreased from approximately 1.84 to $0.008 \mathrm{~kg}$ of water $/ \mathrm{kg} \mathrm{DM}$ and from 1.65 to 0.011 $\mathrm{kg}$ of water $/ \mathrm{kg} \mathrm{DM}$ for both types of greenhouse in just 18 hours and 12 hours, respectively. This recorded time in the two drying periods was significantly lower compared to the that recorded by several previous studies in the literature. The hot season drying study was more relevant; the drying time was the shortest, 18 hours for the open greenhouse and less than 12 hours for the closed greenhouse. This is led to recommend drying in a closed solar greenhouse in the summer season. The high drying speed values were obtained during the hot season with a maximum of $0.7 \mathrm{~kg}$ of water $/ \mathrm{kg}$ MS.h recorded in a closed greenhouse. The digital processing of the $2 \mathrm{D}$ cross-sectional images of sludge samples showed significant reduction in diameter during the first 5 and 10 hours of drying in hot and cold periods, respectively. In addition, shrinkage and cracking phenomena were observed during the drying campaigns carried out. The corresponding volume reduction represented at least $70 \%$ of the initial volume in the two seasons studied. For a full understanding of the drying process under various aerothermal conditions, characteristic drying curves have been made. It is evident that the application of free solar energy would lead to a reduction in the costs of storage, handling and transportation, and would greatly reduce the cost of the drying system in terms of energy consumption. Finally, using solar energy is very promoting especially in a country exposed to a high solar irradiation like Morocco, the studied process allows significant energy savings compared to conventional dryers and seems to have many advantages. Also, the results can be extrapolated easily to an industrial scale, and can be useful to design an industrial and a specific solar dryer to manage this kind of wastes in commercial quantities.

\section{Acknowledgements}

The authors thank Pr.Laila Mandi the director of the National Center for Studies and Research on Water and Energy (CNEREE) in Marrakech.

\section{References}

1. FANTASSE A., LAKHAL E.K., IDLIMAM A., KOUHILA M., BERROUG F., EL HALOUI Y. Management of hydroxide sludge waste using hygroscopic gravimetric method and physico-chemical characterization, Mater. Today Proc., 2020, doi: 10.1016/j. matpr.2020.03.498.

2. CHAHID L., YAACOUBI A., BACAOUI A., LAKHAL E. Valorization of drinking water treatment sludge (DWTS): Characterization and applications as coagulant and sorbent for Olive Mill Wastewater (OMW), J. Mater. Environ. Sci., 6 (9), 2520, 2015.

3. BENLALlA A., ELMOUSSAOUITI M., CHERKAOUI M., AIT HSAIN L., ASSAFI M. Characterization 
and valorization of drinking water sludges applied to agricultural spreading, J. Mater. Environ. Sci., 6 (6), 1692, 2015.

4. BELLOULID M.O., HAMDI H., MANDI L., OUAZZANI N. Solar drying of wastewater sludge: a case study in Marrakesh, Morocco, Environ. Technol., 40 (10), 1316, Apr. 2019, doi: 10.1080/09593330.2017.1421713.

5. AZEDDINE F., EL KHADIR L., ALI I., FATIHA B. Energy efficiency of drying kinetics process of hydroxide sludge wastes in an indirect convection solar dryer, J. Sol. Energy Eng., 1, 2021, doi: 10.1115/1.4049622.

6. MIRAHMAD A., SADRAMELI S.M. A comparative study on the modeling of a latent heat energy storage system and evaluating its thermal performance in a greenhouse, Heat Mass Transf. und Stoffuebertragung, 54 (9), 2871, Sep. 2018, doi: 10.1007/s00231-018-2316-4.

7. BELLOULID M. O., HAMDI H., MANDI L. Solar Greenhouse Drying of Wastewater Sludges Under Arid Climate, Waste and Biomass Valorization, 8 (1), 193, 2017, doi: 10.1007/s12649-016-9614-1.

8. BARTOSZEWICZ M., MICHALSKA M., CIESZYŃSKASEMENOWICZ M., CZERNYCH R., WOLSKA L. The problem of wastewater in shale gas exploitation: The influence of fracturing flowback water on activated sludge at a wastewater treatment plant, Polish J. Environ. Stud., 25 (5), 1839, Oct. 2016, doi: 10.15244/pjoes/62637.

9. SHRIVASTAVA V., KUMAR A. Experimental investigation on the comparison of fenugreek drying in an indirect solar dryer and under open sun, Heat Mass Transf. und Stoffuebertragung, 52 (9), 1963, Sep. 2016, doi: 10.1007/s00231-015-1721-1.

10. ANTONIOU N., MONLAU F., SAMBUSITI C., FICARA E., BARAKAT A., ZABANIOTOU A. Contribution to Circular Economy options of mixed agricultural wastes management: Coupling anaerobic digestion with gasification for enhanced energy and material recovery, Journal of Cleaner Production, 209, 505, 2019, doi: 10.1016/j.jclepro.2018.10.055.

11. LÉONARD A., BLACHER S., MARCHOT P., PIRARD J. P., CRINE M. Convective drying of wastewater sludges: Influence of air temperature, superficial velocity, and humidity on the kinetics, Dry. Technol., 23 (8), 1667, 2005, doi: 10.1081/DRT-200065082.

12. LEONARD A., BLACHER S., MARCHOT P., CRINE M. Use of X-ray microtomography to follow the convective heat drying of wastewater sludges, Dry. Technol., 20 (4-5), 1053, 2002, doi: 10.1081/DRT-120004013.

13. BENNAMOUN L., CRINE M., LÉONARD A. Convective Drying of Wastewater Sludge: Introduction of Shrinkage Effect in Mathematical Modeling, Dry. Technol., 31 (6), 643, Apr. 2013, doi: 10.1080/07373937.2012.752743.

14. MAHAPATRA A., TRIPATHY P.P. Experimental investigation and numerical modeling of heat transfer during solar drying of carrot slices, Heat Mass Transf. und Stoffuebertragung, 55 (5), 1287, May 2019, doi: 10.1007/ s00231-018-2492-2.

15. PRAKASH O., KUMAR A. Performance evaluation of greenhouse dryer with opaque north wall, Heat Mass Transf. und Stoffuebertragung, 50 (4), 493, Nov. 2014, doi: 10.1007/s00231-013-1256-2.

16. CHAUHAN P. S., KUMAR A., NUNTADUSIT C., MISHRA S.S. Drying Kinetics, Quality Assessment, and Economic Analysis of Bitter Gourd Flakes Drying Inside
Forced Convection Greenhouse Dryer, J. Sol. Energy Eng. Trans. ASME, 140 (5), Oct. 2018, doi: 10.1115/1.4039891.

17. CAI W., ZHU L., DONG S., XIE G., LI J. Effect of Thermophysical Properties on Coupled Heat and Mass Transfer in Porous Material during Forced Convective Drying, Adv. Mech. Eng., 6, p. 830387, 2014, doi: 10.1155/2014/830387.

18. BOURAOUI C. Numerical study of the greenhouse solar drying of olive mill wastewater under different conditions, 12 (4), 1, 2020, doi: 10.1177/1687814019889748.

19. BENNAMOUN L., FRAIKIN J., LI L., LÉONARD A. Forced convective drying of wastewater sludge with the presentation of exergy analysis of the dryer, Chem. Eng. Commun., 203 (7), 855, 2016, doi: 10.1016/j. psep.2016.05.022.

20. AYYAPPAN S., MAYILSAMY K., SREENARAYANAN V.V. Performance improvement studies in a solar greenhouse drier using sensible heat storage materials, Heat Mass Transf. und Stoffuebertragung, 52 (3), 459, Mar. 2016, doi: 10.1007/s00231-015-1568-5.

21. MISHRA S., VERMA S., CHOWDHURY S., DWIVEDI G. Analysis of recent developments in greenhouse dryer on various parameters- a review, Mater. Today Proc., Aug. 2020, doi: 10.1016/j.matpr.2020.07.429.

22. MOUZAOUI M., BAUDEZ J.C., SAUCEAU M., ARLABOSSE P. Experimental rheological procedure adapted to pasty dewatered sludge up to $45 \%$ dry matter, Water Res., 133, 1, Apr. 2018, doi: 10.1016/j. watres.2018.01.006.

23. MAZUMDER D., GOSWAMI S., Kinetic Behaviour of the Activated Sludge Process Used for Treating Composite Chrome Tannery Wastewater, Polish J. Environ. Stud., 24 (6), 2405, Nov. 2015, doi: 10.15244/pjoes/59214.

24. BUX M., BAUMANN R., QUADT S., PINNEKAMP J., MÜHLBAUER W. Volume reduction and biological stabilization of sludge in small sewage plants by solar drying, Dry. Technol., 20 (4-5), 829, Jun. 2002, doi: 10.1081/DRT-120003765.

25. MATHIOUDAKIS V.L., KAPAGIANNIDIS A.G., ATHANASOULIA E., DIAMANTIS V.I., MELIDIS P., AIVASIDIS A. Extended Dewatering of Sewage Sludge in Solar Drying Plants, Desalination, 248 (1-3), 733, Nov. 2009, doi: 10.1016/j.desal.2009.01.011.

26. KUMAR A., TIWARI G.N. Effect of mass on convective mass transfer coefficient during open sun and greenhouse drying of onion flakes, J. Food Eng., 79 (4), 1337, Apr. 2007, doi: 10.1016/j.jfoodeng.2006.04.026.

27. SMOLLEN M. Evaluation of municipal sludge drying and dewatering with respect to sludge volume reduction, in Water Science and Technology, Dec. 1990, 22 (12), 153, doi: 10.2166/wst.1990.0110.

28. PAODE R.D., LIU J.I., HOLSEN T.M. Modeling the Energy Content of Municipal Solid Waste Using Multiple Regression Analysis, J. Air Waste Manag. Assoc., 46 (7), 650, 1996, doi: 10.1080/10473289.1996.10467499.

29. FUDHOLI A., OTMAN M.Y., RUSLAN M.H., YAHYA M., ZAHARIM A., SOPIAN K., Techno-Economic Analysis of Solar Drying System for Seaweed in Malaysia, pp. 89-95.

30. AKPINAR E.K. Drying of parsley leaves in a solar dryer and under open sun: Modeling, energy and exergy aspects, J. Food Process Eng., 34 (1), 27, Feb. 2011, doi: 10.1111/j.1745-4530.2008.00335.x. 